\title{
Colorimetric method for susceptibility testing of voriconazole and other triazoles against Candida species
}

\author{
Kolorimetrische Methode zur Empfindlichkeitsprüfung von \\ Voriconazol und anderen Triazolen für Candida-Arten
}

Carol A. Kauffman and Lidija T. Zarins

Key words. Candida, susceptibility testing, voriconazole, triazoles, colorimetric assay, Alamar Blue.

Schlüsselwörter. Candida, Empfindlichjeitsprüfung, Voriconazol, Triazole, kolorimetrische Methode, Almarblau.

Summary. A microdilution assay using Alamar Blue, a colorimetric indicator, was compared with the NCCLS macrodilution broth assay for voriconazole, fluconazole, and itraconazole against Candida albicans, Candida glabrata, and Candida krusei. Concordance ( \pm 2 dilutions) between the two methods was highest for voriconazole (98.3\%), and for fluconazole and itraconazole it was 94.3 and $95.4 \%$, respectively. Twenty-six of $32(81.2 \%)$ discordant readings ( $\geq 3$ dilutions different) were noted in C. glabrata isolates, and all but two isolates showing discordance had higher minimum inhibitory concentration readings with the colorimetric method.

Zusammenfassung. Ein Mikrodilutionstest unter Verwendung des Farbindikators Alamarblau wurde mit dem NCGLS-Makrodilutionstest zur Empfindlichkeitsprüfung von Candida albicans, $C$. glabrata und C. krusei für Voriconazol, Fluconazol und Itraconazol verglichen. Die Übereinstimmung ( \pm 2 Verdünnungsstufen) war am besten bei Voriconazol (98.3\%), gefolgt von Fluconazol (94.3\%) und Itraconazol (95.4\%). Diskordante Ablesungen ( $\geq 3$ Verdünnungsstufen) traten $26 \mathrm{mal}(81.2 \%)$ bei C. glabrata-Isolaten auf, aber außer zwei zeigten alle diskordanten Isolate höhere MHK-Werte mit der kolorimetrischen Methode.

Division of Infectious Diseases, Department of Internal Medicine, Ann Arbor Veterans Affairs Health System, University of Michigan Medical School, Ann Arbor, MI, USA.

Correspondence: Dr Carol A. Kauffman, VA Medical Center, 2215 Fuller Rd., Ann Arbor, MI 48105, USA. Tel.: (734) 761 7984; fax: (734) 769 7039; e-mail: ckauff@umich.edu

\section{Introduction}

Voriconazole is a new triazole agent that appears to have a broader spectrum of antifungal activity than the parent compound, fluconazole [1-6]. Prior studies that have assessed the in vitro activity of voriconazole against Candida species have utilized the National Committee for Clinical Laboratory Standards (NCCLS) recommended microdilution or macrodilution methods. However, the visual turbidity endpoints of these assays are frequently difficult to define for azole agents. Several species, most notably Candida albicans, exhibit a trailing phenomenon rather than a sharp end-point $[7,8]$.

Alamar Blue (AccuMed, Westlake, OH, USA) is an oxidation-reduction colorimetric indicator that, in the presence of actively growing organisms, changes colour from a deep blue to a bright pink. We and others have previously shown the feasibility of using this system for antifungal susceptibility testing [9-14]. Voriconazole has not previously been tested with this method.

In this study, we compared the results obtained using a colorimetric microdilution method with the NCGLS macrodilution method for isolates of C. albicans, Candida glabrata and Candida krusei against voriconazole, as well as fluconazole and itraconazole.

\section{Methods}

Antifungal drugs

The stock solution of voriconazole (Pfizer, Inc., Groton, CT, USA) was made by dissolving 
the powder in dimethyl sulfoxide (DMSO). Fluconazole (Pfizer, Inc.) was dissolved in sterile distilled water. Itraconazole (Janssen Research Foundation, Beerse, Belgium) was solubilized in DMSO. All stock solutions were stored at $-70{ }^{\circ} \mathrm{C}$ and then thawed and diluted in RPMI-1640 (Sigma, St. Louis, MO, USA) on the day that the test was performed.

\section{Fungal isolates}

Isolates of C. albicans, C. glabrata and C. krusei were obtained between 1981 and 1997 from our patient populations, including those who had neutropenia [15, 16] or HIV infection [17] and those who were in an intensive care unit or a nursing home [18]. The isolates from the 1980s had been stored at room temperature in distilled water in air-tight containers, and the isolates from 1990 onward were stored at $-70{ }^{\circ} \mathrm{C}$ in Sabouraud glucose broth with glycerol. Each isolate was retrieved from storage and plated twice in succession on Sabouraud glucose agar prior to testing. Two control strains, C. glabrata ATCG 90030 and Candida parapsilosis ATCG 90018, were tested on each day that the minimum inhibitory concentration $(\mathrm{MIC})$ levels were determined.

\section{Susceptibility testing}

The NCGLS broth macrodilution method was performed as outlined in the M27-A document [19]. Briefly, RPMI 1640 medium with morpholinepropanesulfonic acid (MOPS) buffer (Sigma), was used at a final $\mathrm{pH}$ of 7.0. The final inoculum was $0.5 \times 10^{3}$ to $2.5 \times 10^{3}$ yeast cells ml ${ }^{-1}$; the total volume was $1 \mathrm{ml}$. Tubes were incubated at $35{ }^{\circ} \mathrm{C}$ for $48 \mathrm{~h}$. The MIC was the drug concentration at which visual turbidity was less than or equal to that of the comparison tube that consisted of a $1: 5$ dilution of the growth control $(80 \%$ growth suppression). Concentrations of fluconazole ranged from 0.06 to $64 \mu \mathrm{g} \mathrm{ml}^{-1}$; itraconazole and voriconazole ranged from 0.007 to $4 \mu \mathrm{g} \mathrm{ml}^{-1}$.

The Alamar Blue modified NCGLS microdilution method was performed as described previously [12]. The reagents, medium preparation, inoculum and drug concentrations were the same as noted above for the macrodilution method with two exceptions: Alamar Blue $(1 \mu \mathrm{l}$ of $100 \times$ reagent) was added to each $1 \mathrm{ml}$ of RPMI 1640-MOPS medium prior to inoculation of the yeast, and U-bottom, 96-well, microtitre plates were used for the assay. To each well was added $180 \mu \mathrm{l}$ of RPMI 1640-MOPS with Alamar Blue containing $0.5 \times 10^{3}$ to $2.5 \times 10^{3}$ yeast cells and $20 \mu \mathrm{l}$ of the appropriate concentration of drug. The plates were incubated at $35^{\circ} \mathrm{C}$ for $48 \mathrm{~h}$. The MIC was determined as the lowest drug concentration that maintained a blue or a blue-pink hue. Wells with growth were pink-red in

colour.

\section{Results}

A total of 137 isolates of C. albicans, 124 isolates of C. glabrata, and 20 isolates of C. krusei were studied by both methods. Comparing the two methods, $\mathrm{MIC}_{50}$ and $\mathrm{MIC}_{90}$ results differed by $\leq 1$ dilution for the three triazoles for each of the three Candida species (Table 1). Major discordance ( $\geq 3$ dilutions different) between the two methods occurred on only 32 determinations (Table 2 ). The discordance was most marked for C. glabrata (26 of 32 discordant readings) and with MIC determinations for itraconazole and fluconazole. Only three isolates (all C. albicans) showed major discor-

\begin{tabular}{|c|c|c|c|c|c|c|c|c|c|}
\hline \multirow[t]{3}{*}{ Organism (no.) } & \multicolumn{9}{|c|}{ Minimum inhibitory concentration $\left(\mu \mathrm{g} \mathrm{ml}{ }^{-1}\right)$} \\
\hline & \multicolumn{3}{|c|}{ Voriconazole } & \multicolumn{3}{|c|}{ Itraconazole } & \multicolumn{3}{|l|}{ Fluconazole } \\
\hline & Range & $\mathrm{MIC}_{50}$ & $\mathrm{MIC}_{90}$ & Range & $\mathrm{MIC}_{50}$ & $\mathrm{MIC}_{90}$ & Range & $\mathrm{MIC}_{50}$ & $\mathrm{MIC}_{90}$ \\
\hline \multicolumn{10}{|l|}{ C. albicans (137) } \\
\hline macro & $0.007-2$ & 0.01 & 0.03 & $0.01->4$ & 0.06 & 0.12 & $0.06->64$ & 0.25 & 1 \\
\hline Alamar & $0.007-2$ & 0.01 & 0.06 & $0.01->4$ & 0.06 & 0.12 & $0.12-32$ & 0.5 & 1 \\
\hline \multicolumn{10}{|l|}{ C. glabrata (124) } \\
\hline macro & $0.06->4$ & 1 & 2 & $0.06->4$ & 1 & 4 & $0.5->64$ & 8 & 32 \\
\hline Alamar & $0.06->4$ & 1 & 2 & $0.25->4$ & 1 & 4 & $2->64$ & 16 & 32 \\
\hline \multicolumn{10}{|l|}{ C. krusei (20) } \\
\hline macro & $0.25-2$ & 0.5 & 2 & $0.12->4$ & 2 & 4 & $32->64$ & 64 & $>64$ \\
\hline Alamar & $0.25-2$ & 1 & 2 & $0.25->4$ & 2 & 4 & $32->64$ & 64 & $>64$ \\
\hline
\end{tabular}




\begin{tabular}{|c|c|c|c|c|c|c|}
\hline \multirow[t]{2}{*}{ Organism (no.) } & \multicolumn{2}{|c|}{ Voriconazole } & \multicolumn{2}{|c|}{ Itraconazole } & \multicolumn{2}{|c|}{ Fluconazole } \\
\hline & \pm 2 dil & \pm 3 dil & \pm 2 dil & \pm 3 dil & \pm 2 dil & \pm 3 dil \\
\hline C. albicans (137) & $126(92)$ & $134(98)$ & $123(90)$ & $136(99)$ & $122(89)$ & $135(99)$ \\
\hline C. glabrata (124) & $116(94)$ & $124(100)$ & $100(81)$ & $112(90)$ & $99(80)$ & $110(89)$ \\
\hline C. krusei (20) & $17(85)$ & $20(100)$ & $19(95)$ & $20(100)$ & $20(100)$ & $20(100)$ \\
\hline
\end{tabular}

dance for voriconazole. For 30 of the 32 major discordant readings, the colorimetric reading was higher than the NCCLS macrodilution reading. For all three triazoles, the colorimetric change was not completed by $24 \mathrm{~h}$ for many isolates, especially $C$. glabrata isolates, which tended to grow more slowly. By $48 \mathrm{~h}$, the colour changes were clear-cut and able to be read reproducibly. Some, but not all, isolates that demonstrated trailing and were difficult to read by the $80 \%$ visual turbidity endpoint also showed gradations of mauve-topurple, rather than clear-cut red-blue endpoints,

by the colorimetric assay.

\section{Discussion}

In this study, we found that a colorimetric assay utilizing the Alamar Blue reagent was comparable with the NCCLS macrodilution broth method for voriconazole, as well as the other triazoles, fluconazole and itraconazole. Major discrepancies between the two methods were uncommon and were found most often for C. glabrata. With both methods, the voriconazole endpoints were the most clear-cut of the three triazoles. This could reflect the ability of this new triazole to more effectively inhibit yeasts when compared with the older triazoles.

We verified by the colorimetric method the results of an earlier study using some of these same isolates [4] that voriconazole had lower $\mathrm{MIC}_{50}$ values than fluconazole for all three species of Candida, and had lower $\mathrm{MIC}_{50}$ values than itraconazole for both C. albicans and C. krusei, but not for C. glabrata. These data are similar to those reported previously by others $[1-3,5]$.

The NCCLS method has gained wide acceptance and has standardized the approach to yeast susceptibility testing. However, the visual endpoints for both micro and macro methods may be difficult to read. The colorimetric method utilizing Alamar Blue offers a different method for endpoint determination. The colorimetric endpoints were easier to read than the turbidity endpoints of the NCGLS method. However, there were problematic isolates of $C$. albicans that showed trailing by the NCCLS method and that also demonstrated 'colorimetric trailing', manifested by mauve hues rather than discrete red-blue endpoints, by the Alamar Blue assay.

Recently, Rex et al. in an attempt to correlate in vitro susceptibility testing with in vivo efficacy in an animal model, noted that 24-h MIC readings may be more appropriate than $48-\mathrm{h}$ readings for Candida species [8]. Similarly, Revankar et al. identified several strains that exhibited trailing and for which 24-h readings matched better with clinical outcome than 48-h readings [7]. However, we and others [14] have found that the colorimetric readings were not fully developed at $24 \mathrm{~h}$, especially for the more slowly growing C. glabrata isolates. Thus, for 48-h readings, the Alamar Blue colorimetric assay appears to be a useful addition to yeast susceptibility testing, but 24-h endpoints were not enhanced with this method. If further correlations of in vivo response to triazoles show that 24-h MIC readings correlate better with outcome, then the colorimetric method will not

enhance in vitro susceptibility testing.

\section{Acknowledgements}

This study was made possible by a grant from

Pfizer, Inc.

\section{References}

1 Ruhnke, M., Schmidt-Westhausen, A. \& Trautmann, M. (1997) In vitro activities of voriconazole (UK-109,496) against fluconazole-susceptible and-resistant Candida albicans from oral cavities of patients with human immunodeficiency virus infection. Antimicrob. Agents Chemother. 41, 575-577.

2 Barry, A. L. \& Brown, S. D. (1996) In vitro studies of two triazole antifungal agents (Voriconazole [UK-109,496] and fluconazole) against Candida species. Antimicrob. Agents Chemother. 40, 1948-1949. 
3 Espinel-Ingroff, A. (1998) In vitro activity of a new triazole voriconazole (UK-109,496) against opportunistic filamentous and dimorphic fungi in common and emerging yeast pathogens. F. Clin. Microbiol. 36, 198-202.

4 Kauffman, C. A. \& Zarins, L. T. (1998) In vitro activity of voriconazole against Candida species. Diagn. Microbiol. Infect. Dis. 31, 297-300.

5 Marco, F., Pfaller, M. A., Messer, S. \& Jones, R. N. (1998) In vitro activities of voriconazole (UK-109,496) and four other antifungal agents against 394 clinical isolates of Candida spp. Antimicrob. Agents Chemother. 42, 161-163.

6 McGinnis, M. R., Pasarell, L., Sutton, D. A., Fothergill, A. W., Cooper, C. R. \& Rinaldi, M. G. (1997) In vitro evaluation of voriconazole against some clinically important fungi. Antimicrob. Agents Chemother. 41, 1832-1834.

7 Revankar, S. G., Kirkpatrick, W. R., McAtee, R. K., et al. (1998) Interpretation of trailing endpoints in antifungal susceptibility testing by the National Committee for Clinical Laboratory Standards methods. 7. Clin. Microbiol. 36, 153-156.

8 Rex, J. H., Nelson, P. W., Paetznick, V. L., LozanoChiu, M., Espinel-Ingroff, A. \& Anaissie, E. J. (1998). Optimizing the correlation between results of testing in vitro and therapeutic outcomes in vivo for fluconazole by testing critical isolates in a murine model of invasive candidiasis. Antimicrob. Agents Chemother. 42, 129-134.

9 Pfaller, M. A., Grant, C., Morthland, V. \& RhineChalberg, J. (1994) Comparative evaluation of alternative methods for broth dilution susceptibility testing of fluconazole against Candida albicans. 7. Clin. Microbiol. 32, 506-509.

10 Pfaller, M. A., Vu, Q., Lancaster, M., et al. (1994) Multisite reproducibility of colorimetric broth microdilution method for antifungal susceptibility testing of yeast iso(1997) Reference method for broth dilution antifungal susceptibility lates. F. Clin. Microbiol. 32, 1625-1628.

11 Pfaller, M. A. \& Barry, A. L. (1994) Evaluation of a novel colorimetric broth microdilution method of antifungal susceptibility testing of yeast isolates. 7. Clin. Microbiol. 32, 1992-1996.

12 Tiballi, R. N., Zarins, L. T., He, X. \& Kauffman, C. A. (1995) Torulopsis glabrata: azole susceptibilities by microdilution colorimetric and macrodilution broth assays. 7. Clin. Microbiol. 33, 2612-2615.

13 Tiballi, R. N., He, X., Zarins, L. T., Revankar, S. G. \& Kauffman, C. A. (1995) Use of a colorimetric system for yeast susceptibility testing. F. Clin. Microbiol. 33, 915-917.

14 Arikan, S., Gür, D. \& Akova, M. (1997) Comparison of Etest, microdilution and colorimetric dilution with reference broth macrodilution method for antifungal susceptibility testing of clinically significant Candida species isolated from immunocompromised patients. Mycoses $\mathbf{4 0}$, 291-296.

15 Jones, P. G., Kauffman, C. A., McAuliffe, M. S., Liepman, M. K. \& Bergman, A. G. (1984) Efficacy of ketoconazole versus nystatin for the prevention of fungal infections in neutropenic patients. Arch. Intern. Med. 144, 549-551.

16 Kauffman, C. A., Liepman, M. K., Bergman, A. G. \& Mioduszewski, J. (1983) Trimethoprim/sulfamethoxazole prophylaxis in neutropenic patients: reduction of infection and effect on bacterial and fungal flora. Am. F. Med. 74, 599-607.

17 Sangeorzan, J. A., Bradley, S. F., He, X., et al. (1994) Epidemiology of oral candidiasis in HIV-infected patients: colonization, infection, treatment, and emergence of fluconazole resistance. Am. F. Med. 97, 339-347.

18 Hedderwick, S. A., Wan, J. Y., Bradley, S. F., Sangeorzan, J. A., Terpenning, M. S. \& Kauffman, C. A. (1998) Risk factors for colonization with yeast species in a long-term care facility. 7. Am. Geriatr. Soc. 46, 849-853.

19 National Committee for Clinical Laboratory Standards. 